\title{
Histopathological Grading and Enzyme Histochemical Study of the Placenta in Gestational Diabetes Mellitus Pregnant Women
}

\author{
Sahar A. H. AL-Sharqi ${ }^{1}$, Amal Kadhem Chaloob ${ }^{2}$, Ilham Abd Allah Ali Al-Saleem ${ }^{3}$ \\ ${ }^{1}$ Assistant Professor, Department of Biology, College of Science, Mustansiriyah University, Baghdad/Iraq, \\ ${ }^{2}$ Assistant Professor, Department of Basic Science, College of Dentistry, Mustansiriyah University, Baghdad/Iraq, \\ ${ }^{3}$ Lecturer, Department of Biology, College of Science, Al-Mosul University, Mosul/Iraq
}

\begin{abstract}
Gestational diabetes mellitus (GDM) constitutes carbohydrate metabolism disorders that lead to severe and sometimes life-threatening complications of pregnancy.

Materials and Method: 40 placenta biopsies with blood samples were taken from gestational diabetic pregnant women and 20 placenta biopsies with blood samples were taken from healthy pregnant women, the tissues were fixed, processed, embedded and cutting separately depending on procedure for enzyme histochemical and routine histological technique and the blood was centrifuged.

Results: The histological changes in the GDM group represented by villous oedema in approximately (30\%) of the GDM group, an excessive amount of collagen fibres in the villous stroma (57.5\%). Syncytial knots were formed $(70 \%)$ in addition to an excessive number of cytotrophoblast cells in about (65\%). The stromal fibrinoid deposition was noticed in (52.5\%). Hypo-vascular villi are seen in $(32.5 \%)$ also, atherosis of the uteroplacental arteries in (40\%) of biopsies. In enzyme histochemistry, the villous stroma of the GDM group has a strong reaction to the G-6-P enzyme. There is a significant increase $(\mathrm{p}<0.05)$ in serum blood sugar, cholesterol, blood urea in the GDM group when compared with the normoglycemic group.
\end{abstract}

Conclusions: The increment of serum blood sugar caused histological and enzyme histochemical alteration during pregnancies.

Keywords: Gestational Diabetes Mellitus, placenta, Histopathological, Enzyme histochemical.

\section{Introduction}

Gestational diabetes mellitus (GDM) is defined as a condition of glucose intolerance that appears during pregnancy ${ }^{1}$. This type of diabetes accompanies the pregnancy period and disappears after birth. It is a medical complication that affects about $3-10 \%$ of

\section{Corresponding Author:}

Sahar A. H. AL-Sharqi

Assistant Professor, Department of Biology, College of Science, Mustansiriyah University, Baghdad/Iraq e-mail: saharalsharqi@uomustansiriyah.edu.iq pregnant women, and it appears more in women with a family history of the disease. ${ }^{2}$

Diabetes occurs during the second trimester of pregnancy ${ }^{3}$, but most of it occurs in the third trimester of pregnancy, as the mother is likely to develop diabetes after childbirth, especially type- 2 diabetes mellitus ${ }^{4}$. The causes of GDM in some women are not known in a specific way, but there are contributing factors in the occurrence of the disease, including the interference of the hormones required by the fetus's growth that is an obstacle to the work of insulin $\mathbf{5}$, and that weight gain may lead to increased insulin resistance and insulin resistance will deprive the fetus of the benefit of the effect of insulin product ${ }^{6}$. The placenta during pregnancy produces 
additional amounts of the hormone (Cortisol) and other hormones that are anti-insulin, such as progesterone and human chorionic gonadotrophin and the human placental lactogen ${ }^{7}$. All of these hormones increase the level of glucose in beta cells. Beta-cells in the pancreas is unable to produce sufficient amounts of insulin to offset this increase in the level of glucose or there was insulin resistance by the mother (Maternal insulin resistance) as this increases the possibility of a case of excess glucose in the pregnant mother (Hyperglycemia) or what it is called GDM ${ }^{8,9}$. The incidence of complications of GDM in Iraq has increased dramatically in recent years and the health importance of pregnant women and the complications that occur during pregnancy.

The current study aimed to identify some of the histopathological, enzyme histochemical and biochemical changes accompanying these complications.

\section{Materials and Method}

Study Samples: The 60 placenta tissue and blood samples were obtained for pregnant women from Baghdad Teaching Hospital and based on the medical diagnosis by the gynaecologist. A questionnaire was completed containing much information about the pregnant woman, the diseases she had during pregnancy and the laboratory tests that were performed. The women under study were divided into two groups:The first group of 40 pregnant women with GDM, age ranging from 2043 years. The second group 20 normoglycemic pregnant women, age ranging from 18-40 years.

Tissues Collection: Placental tissue biopsies were collected and dissected from the central part of the placental bed after normal vaginal deliveries or caesarian section and prepared for histopathological and enzyme histochemical analysis as follows:

The fragments for the histopathological study were then immediately fixed in formalin $10 \%$, dehydrated in a graded ethanol sequence and embedded in paraffin according to a standard protocol, sectioned at $5 \mu \mathrm{m}$ and installed for the staining with Hematoxylin-Eosin (H \& E) on glass slides and examined under the microscope 10. The fragments for enzyme histochemical study were then immediately fixed and dehydrated in a mixture of equal volumes of cold acetone and absolute alcohol for 24 hours for demonstration of Glucose-6-Phosphatase (G-6-Pase) were based on the modified procedure described by ${ }^{11}$.

Blood Samples Collection: The $5 \mathrm{ml}$ of venous blood was drawn for each of the women from the study groups, the blood was placed in a test tube and left at laboratory temperature $15-25^{\circ} \mathrm{C}$ until the thrombus was formed, then the thrombus was separated by the centrifuge at $3000 \mathrm{rpm}$ for five minutes, a serum was withdrawn and preserved $-20^{\circ} \mathrm{C}$ until laboratory tests.

Biochemical test: Serum Glucose, Cholesterol and Urea were determined by an enzymatic method with the commercially available kit (Rondox).

Statistical Analysis: All results are expressed as Mean values \pm Standard Deviation or as N (\%). For computation, we used the SPSS program version 25 for Windows (SPSS Inc., Chicago, IL, USA) software package. Differences were considered as significant if $\mathrm{p}<0.05$.

\section{Results and Discussion}

A-Placental tissues: Placental tissue from normoglycemic, chorionic villi test appeared as vascular villous stroma surrounded by multinucleated syncytiotrophoblastic layer with indistinct cell borders and darkly stained nuclei. Very rarely we have been able to distinguish villous cytotrophoblastic cells that behave as ovoid, greatly variable in thickness, with welldefined cell borders and light cytoplasm staining. The villous stroma consisted of a core of connective tissue that had several bundles of collagen fibres and flattened fibroblasts. There were 2-5 dilated capillaries lined with fetal blood in the villous stroma (Fig. 1A \& B). 


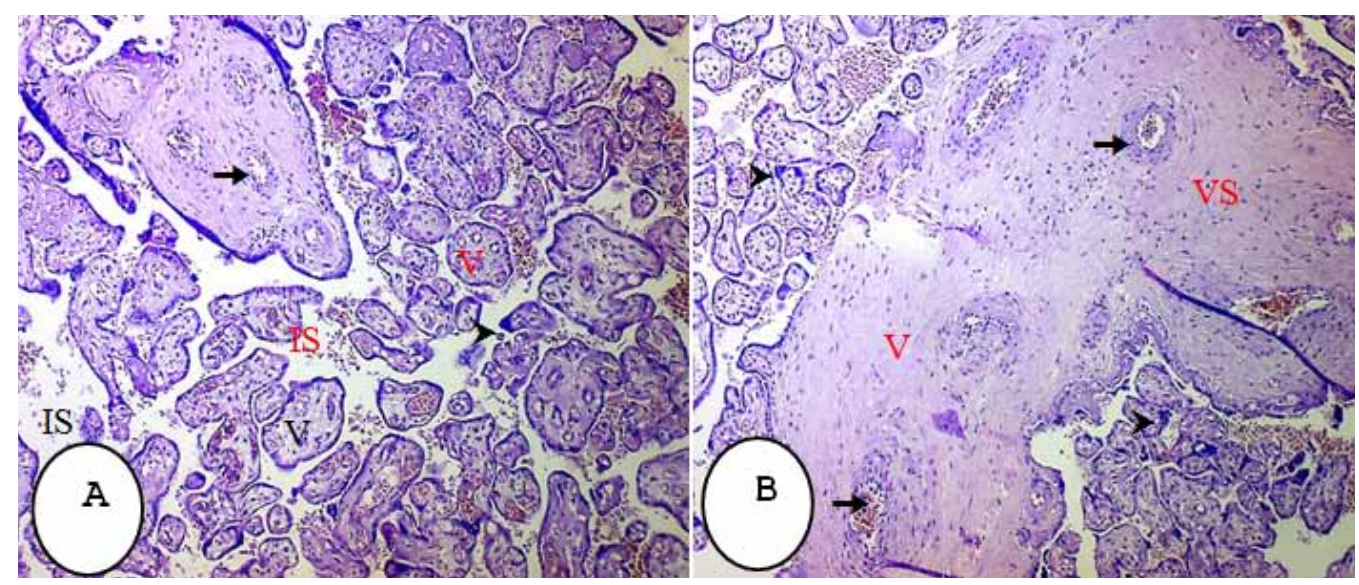

Figure (1): Light microscopical appearance of normoglycemic pregnant women placenta showing microvilli (V) with narrow intervillous spaces (IS) and syncytial knots (head arrows). The villous stroma (VS) shows blood vessels (arrows) containing blood cells, (A \& B: H \& E staining, X10).

All the placenta obtained from the two groups were stained with $\mathrm{H} \& \mathrm{E}$ histological stain. On examination of these sections with a light microscope, our result recognized several histological changes with different proportions. These changes are listed in (Table -1) as following:

Villous oedema was easily seen in the placenta stained, it was seen in 12 placentae (30\%) of the GDM group. However, we couldnst find placentae with villous oedema in the normoglycemic group, (Fig. 2A). Other studies found that one of the pathological features of placentae in hyperglycemic pregnant women is villous oedema ${ }^{12}$. The intervillous distance was of various extent, but some of the distance was vast when compared with normal placentae resulting from intervillous oedema with the increased amount of fibrinoid ${ }^{6}$

On the other hand, an excessive amount of collagen fibres in the stroma of the villi was easily demonstrated, stromal fibrosis was observed in 2 placentae $(10 \%)$ of the normoglycemic group, but increased up to 23 placentae (57.5\%) from GDM group, (Fig. 2B). This results matched with other studies that observed a histological change in GDM placentae represented by stromal fibrosis ${ }^{6}$

Syncytial knots were formed in more than onethird of the examined villi, in 28 placentae $(70 \%)$ from the GDM group. However, this deviation from the normoglycemic group was noticed only in 4 placentae (20\%) (Fig. 2C). More than previous paper observed Syncytial knots in placentae of GDM pregnant women ${ }^{6,13}$. Immoderate forming Syncytial knots is a relationship with placental pathology, and a knotting indicator is employed to estimate riskiness. ${ }^{14}$

In GDM group cases an excessive number of cytotrophoblast cells have been frequently observed. This change was observed in the normoglycemic group in only 2 placentae $(10 \%)$, in the GDM group in 26 placentae $(65 \%)$. El Sawy et al ${ }^{6}$ and other study ${ }^{15}$ confirm that one of indicator of placentae tissue of GDMpregnant is cytotrophoblast cells proliferation ${ }^{6}$.

Stromal fibrinoid deposition affecting of the villi was observed in the normoglycemic group 4 placenta (20\%). Although it was found in 21 placentae (52.5\%) in placentae obtained from the GDM group, (Fig. 2D). Another study confirms that the morphological feature of villous tissue in GDM of women is fibrin deposite ${ }^{13}$. Hypo-vascular villi are seen in 3 placentae $(15 \%)$ of the normoglycemic group and 13 placentae $(32.5 \%)$ of the GDM group, (Fig. 2E). A study on placentae tissue in hyperglycemic pregnancy noticed alterations in vascularity repeating by surprisingly hypovascular and these had a smaller diameter and show a wavy course compared with normal villi. ${ }^{16}$ Also, atherosis of the uteroplacental arteries appears as multiple foamy cells within the walls of the vessels. It was seen only in one placenta from the normoglycemic group $(5 \%)$, and in 16 placentae (40\%) from the GDM group, (Fig. 2F). A study found that placental atherosclerosis occurred in $28.94 \%$ of the group with GDM compared to $10.52 \%$ of the group with normoglycemic pregnancy ${ }^{17}$. 
Table 1: Histological grading of placental tissues in GDM and normoglycemic groups

\begin{tabular}{|l|c|c|c|}
\hline Histological finding & Normoglycemic group $\mathbf{N}=\mathbf{2 0}(\mathbf{\%})$ & GDM group N = 40 (\%) & P-Value \\
\hline Villous edema & $0(0 \%)$ & $12(30 \%)$ & 0.01 \\
\hline Stromal fibrosis & $2(10 \%)$ & $23(57.5 \%)$ & 0.01 \\
\hline Syncytial knots & $4(20 \%)$ & $28(70 \%)$ & 0.01 \\
\hline Cytotrophoblastic cell hyperplasia & $2(10 \%)$ & $26(65 \%)$ & 0.01 \\
\hline Fibrinoid deposition & $4(20 \%)$ & $21(52.5 \%)$ & 0.01 \\
\hline Hypo-vascular villi & $3(15 \%)$ & $13(32.5 \%)$ & 0.01 \\
\hline Atherosis of uteroplacental vessels & $1(5 \%)$ & $16(40 \%)$ & 0.01 \\
\hline
\end{tabular}

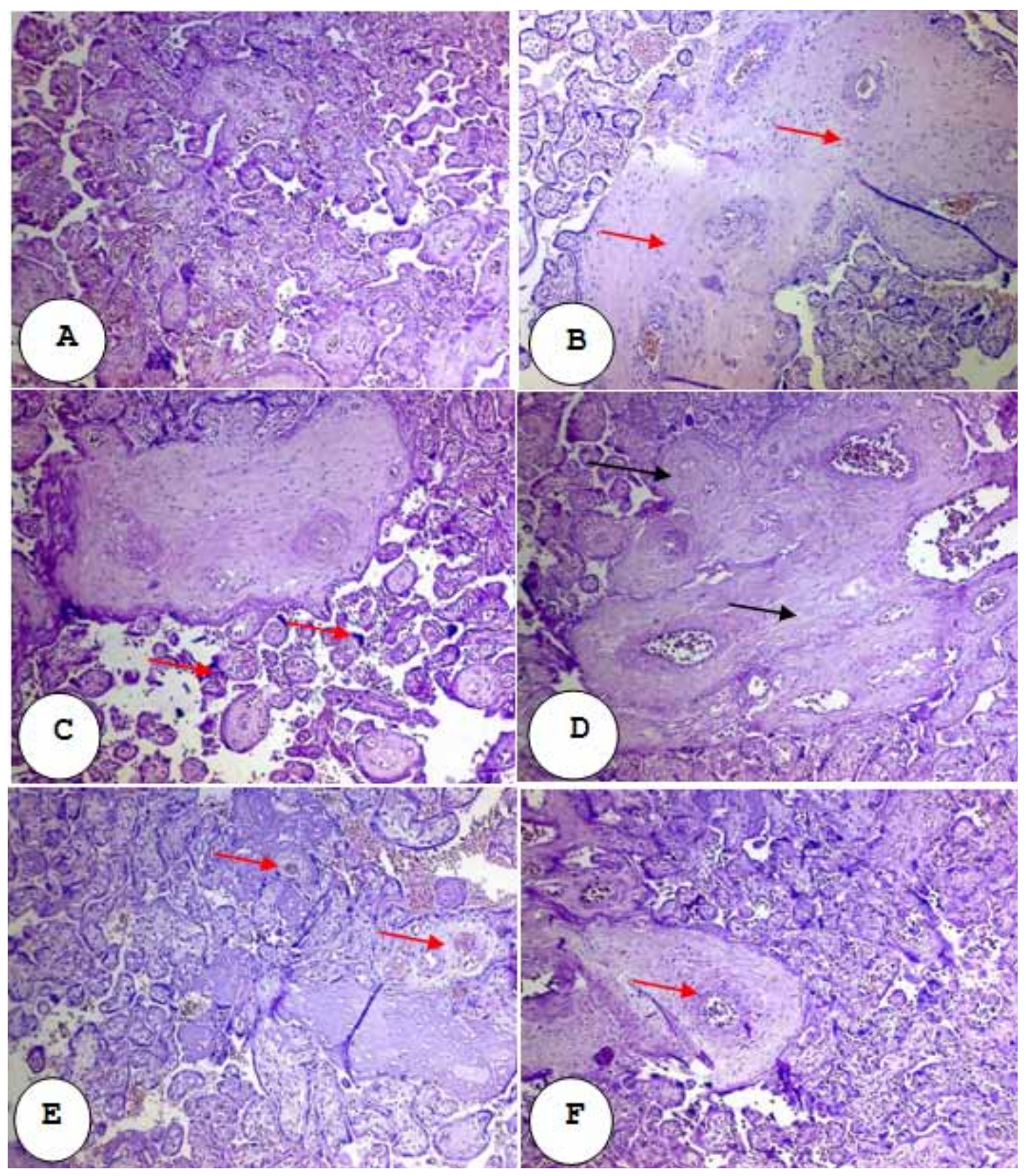

Figure (2): Light microscopical appearance of GDM placenta showing, (A): Villous oedema (B): stromal fibrosis (red arrows),(C): Syncytial knots (red arrows), (D): Fibrinoid deposition (black arrows),(E): Hypovascular villi (red arrows), (F): Atherosis of uteroplacental vessels (A \& B: H \& E X10). 
B-Enzyme histochemical of Glucose-6phosphatase: The placental tissues acquired from normoglycemic women or other maternal disorders exhibiting a weak reaction to the enzyme G-6-Pase (Fig. $3 \mathrm{~A} \& \mathrm{~B})$. The villous stroma showed more dense activity to the G-6-Pase (Fig. 3C \& D), while the trophoblastic showed moderate activity to G-6-Pase in the placental tissue of GDM pregnancy (Fig. 3E \& F). The G-6-Pase plays the important role of supporting glucose during starvation, an enzyme product mainly in the kidney and the ${ }^{18}$. The moderate reactive with normoglycemic proof that it presents in the placenta and this was in a match with other studies that detect the G-6-Pase histochemically in the syncytiotrophoblasts of the placenta ${ }^{19}$. In our study we found that there is a strong activity of the enzyme in hyperglycemic tissue, the previous result confirms that by documentation 2-3 fold increasing the activity of G-6Pase in the liver of diabetic ${ }^{20}$. G-6-Pase is an enzyme that analysis Glucose 6-phosphate, lead to the formation of a free glucose and phosphate group. ${ }^{21}$ When the activity of G-6-Pase increases, free glucose also increases and our results from the increased blood sugar in hyperglycemic pregnancy supporting these results.

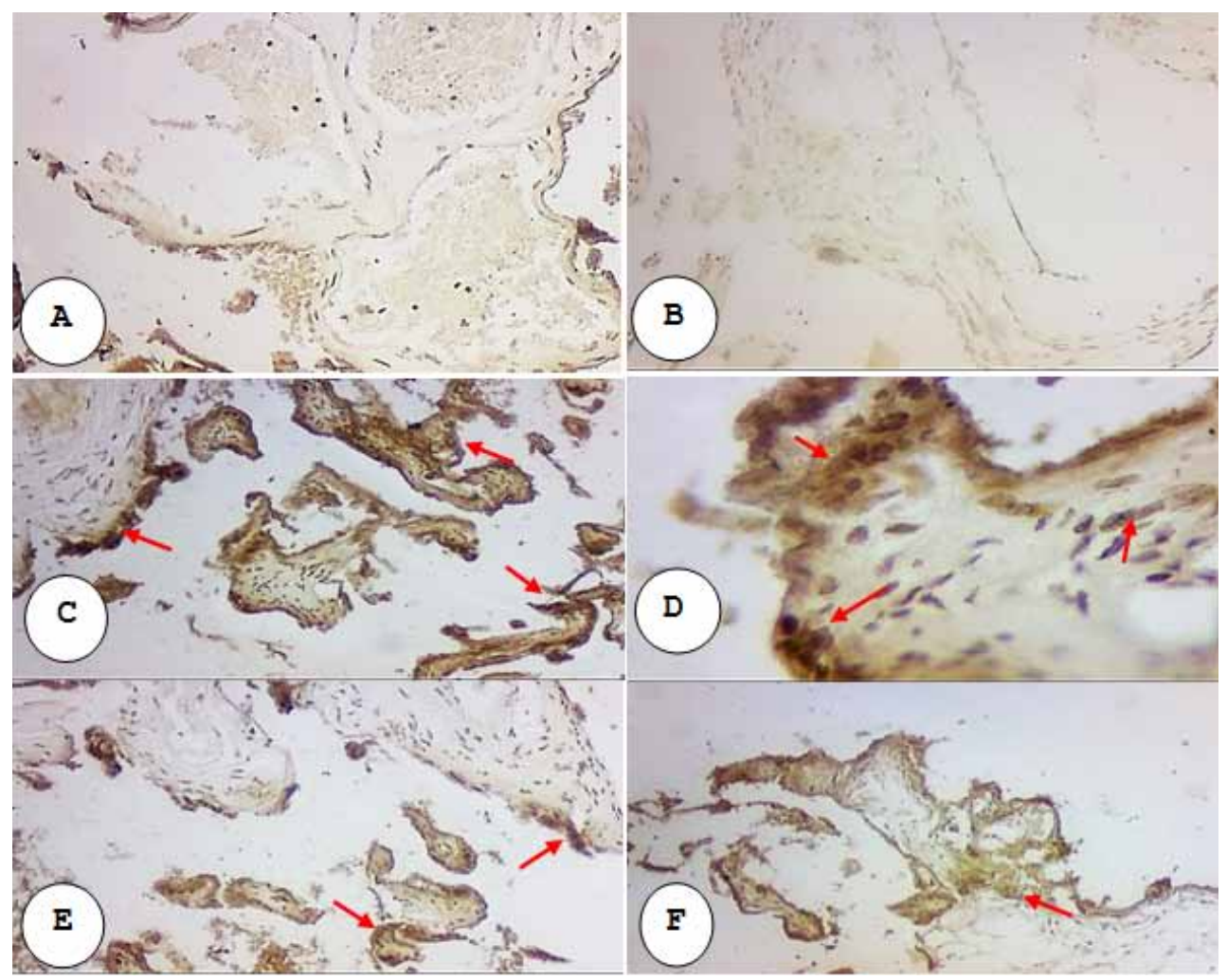

Figure (3): The light microscopical appearance of placental tissue: A \& B obtained from normoglycemic showing a weak reaction to the G-6-Pase (arrows), $C \&$ D: strong reaction to the G-6-Pase in syncytiotrophoblast (red arrows) and cytotrophoblast cells, $\mathrm{E} \& \mathrm{~F}$ : moderate reaction to the G-6-Pase, in placenta GDM(G-6-Pase, X10).

C-Biochemical study: The serum level of glucose for both healthy pregnant women and GDM pregnancy is shown in (Table -2). A significant $(\mathrm{p}<0.05)$ increase is found in the mean value of the glucose in GDM pregnancy $(173.82 \pm 2.47 \mathrm{mg} / \mathrm{dl})$ compared with that of the healthy pregnancy $(84.04 \pm 2.3 \mathrm{mg} / \mathrm{dl})$.

High glucose or diabetes during pregnancy may be caused by a decrease or resistance to the hormone insulin by placenta hormones such as progesterone or human placental lactogen, or as a result of the increase in the secretion of the hormone cortisol that occurs during pregnancy ${ }^{(22,23)}$. Jansson et $\mathrm{al}^{24}$ showed that the high level of glucose from its normal level leads to an increase in its transmission to the placenta. Also, the imbalances in carbohydrate metabolism during pregnancy lead to many complications for the mother 25 . 
While the serum cholesterol level is found to be significantly $(p<0.05)$ increased in the mean of GDM pregnancy when compared with that of a healthy pregnancy. Table (2) showed the mean of GDM pregnancy to be $(224.50 \pm 7.68 \mathrm{mg} / \mathrm{dl})$, while in a healthy pregnancy is $(184.80 \pm 4.34 \mathrm{mg} / \mathrm{dl})$. The increase of total cholesterol level in the serum of women with GDM in the current study supports the results study of Quinlivan and $\mathrm{Lam}^{\mathbf{2 6}}$, and its rise can be attributed to the occurrence of a disorder of fat metabolism ((Dyslipidemia) as a result of the disease ${ }^{27}$. Several studies have shown approaches during the and beyond the pregnancy, adverse metabolic consequences of diabetes ${ }^{28}$.

Recently, the high levels of cholesterol can cause atherosclerosis, research has shown that low density lipoprotein cholestrol LDL-C is not the only type of cholesterol that increases the risk of atherosclerosis, and that any non-HDL-C cholesterol, such as verylow-density lipoprotein cholesterol (VLDL-C) and apolipoprotein $\mathrm{B}$, that increase that risk $^{29}$. Study of Ryckman et al.$^{30}$ found that women with previous GDM Insulin resistance elevate the VLDL-C abnormalities contained in non-high-density lipoprotein cholesterol
(HDL-C) along with (LDL-C) and lipoprotein of intermediate density.

Recently, blood urea has been documented to be associated with diabetes mellitus(DM), commonly regarded as one of the markers of kidney functions ${ }^{31}$. On the one hand, (DM) cause kidney disease, and on the other hand, kidney disease may increase the risk of (DM), including urea or other uraemic elements ${ }^{32,33}$. Our result showed the level of serum urea shows an increase in GDM pregnancy as compared with a healthy pregnancy, (Table 2). The mean value of serum urea in GDM pregnancy is found to be $(28.12 \pm 1.06 \mathrm{mg} / \mathrm{dl})$, and in a healthy pregnancy is $(21.5 \pm 1.2 \mathrm{mg} / \mathrm{dl})$. Statistically, there is a significant $(p<0.05)$ difference between the two groups.

This result is consistent with many researchers who indicated that the GDM condition leads to a rise in the level of urea in the blood serum, and this rise is due to the physiological change as a result of the pathological condition which leads to a decrease in the rate of glomerular filtration rate (GFR). This causes a rise in the level of urea in the blood serum ${ }^{34,35}$.

Table-2: Serum Glucose, Cholesterol and Urea level in GDM and Normoglycemic women.

\begin{tabular}{|l|c|c|c|}
\hline Study Groups & Glucose (mg/dl) & Cholesterol (mg/dl) & Urea (mg/dl) \\
\hline Pregnant women with GDM & $173.82 \pm 2.47$ & $224.50 \pm 7.68$ & $28.12 \pm 1.06$ \\
\hline Normoglycemic women & $84.04 \pm 2.3$ & $184.80 \pm 4.34$ & $21.5 \pm 1.2$ \\
\hline
\end{tabular}

\section{Conclusions}

The hyperglycemia during pregnancy leads to the serious histological changes in placentae representing by oedema in stromal villi, fibrinoid deposition, hypovascular, atherosis of uteroplacental arteries. The villous stroma showed more dense activity to the G-6-P enzyme that indicates to increase the sugar content in it and the study found a strong relationship between hyperglycemia during pregnancy and the rise of serum cholesterol and urea in blood serum.

Ethical Clearance: This study was agreed by the Ethics and Research Committee of the Baghdad Teaching Hospital, Mdical city, Bagdad,Iraq.

Source of Funding: This research was not funded by association.

\section{Conflict of Interest: None}

\section{References}

1. Michelle C, Michael P, Clyde R, Gernot D, Martha L. Defective insulin signalling in placenta from pregnancies complicated by gestational diabetes mellitus. European Journal of Endocrinology. 2009; 160: 567-578.

2. Qazi A, Amin F, Aneela Q, and Mazhar ul H. Gestational diabetes mellitus; still a great problem. Professional Med J. 2016;23(1): 015-019.

3. Barke TL, Goldstein JA, Sundermann AC, Reddy AP, Linder JE, Correa H, Velez-Edwards DR, and Aronoff DM. Gestational diabetes mellitus is associated with increased CD163 expression and iron storage in the placenta. Am J Reprod Immunol. 
2018 ; 80(4): e13020. doi:10.1111/aji.13020.

4. Plows JF, Stanley JL, Baker PN, Reynolds CM and Vickers MH. The Pathophysiology of Gestational DiabetesMellitus. Int. J. Mol. Sci. 2018, 19, 3342

5. MartinoJ, SebertS, Segura MT, García-ValdésL, Florido J, PadillaMC,MarcosA, RuedaR, McArdle HJ and BudgeH, Symonds ME, and Campoy C. Maternal Body Weight and Gestational Diabetes Differentially Influence Placental and Pregnancy Outcomes. J Clin Endocrinol Metab, January 2016, 101(1):59-68. doi: 10.1210/jc.2015-2590.

6. El Sawy ,N.A. Iqbal,MS and Alkushi, AG.Histomorphological Study of Placenta in Gestational Diabetes Mellitus. Int. J. Morphol., 2018;36(2):687-692.

7. Castillo-Castrejon M, and Powell TL. Placental nutrient Transport in Gestational Diabetic Pregnancies. Frontiers in Endocrinology. 2017 ; 8 : Article 306. doi: 10.3389/fendo.2017.00306.

8. Desoye $G$ and Hauguel-de Mouzon SH. The Human Placenta in Gestational Diabetes Mellitus. Diabetes care, 2007;30( Supplement2): 5120-5126.

9. Mejia JF, Hirschi KM, Tsai KYF, Long MG, TullisBC, Eliza E. K. BitterEEK, etal. Differential placental ceramide levels during gestational diabetes mellitus (GDM). Reproductive Biology and Endocrinology (2019) 17:81. https://doi. org/10.1186/s 12958-019-0523-6

10. Suvaran SK,Layton C and Bancroft JD. Bancroft's theory and practice of histological techniques. Eight edition, Churchill livingstone Elsevier.2019.

11. Vacca, L.L. Laboratory manual of histochemistry. Raven press books, Ltd:1985: 308-310.

12. TewariV, Tewari A and BhardwajN. Histological and histochemical changes in placenta of diabetic pregnant females and its comparision with normal placenta . Asian Pacific Journal of Tropical Disease. $2011 ; 1(1): 1-4$

13. Meng Q, Shao L, Luo X, Mu Y, Xu W, GaoC, Gao L, Liu J, and CuiY. Ultrastructure of Placenta of Gravidas with Gestational Diabetes Mellitus. Obstet Gynecol Int. Volume 2015, Article ID 283124, 9 pages http://dx.doi.org/10.1155/2015/283124

14. Fogarty NME, Ferguson-Smith $\mathrm{AC}$ and Burton GJ. Syncytial Knots (Tenney-Parker Changes) in the Human Placenta: Evidence of Loss of Transcriptional Activity and Oxidative Damage.
The American Journal of Pathology. 2013; 183(1):144-152.

15. Aires MB and Veríssimo dos SantosAC. Effects of maternal diabetes on trophoblast cells. World J Diabetes. 2015; 6(2): 338-344.

16. Jirkovská $\mathrm{M}, \mathrm{Ku}$ _cera $\mathrm{T}$, Kaláb J, Jadrní_cek M, Niedobová V, Janá_cek J, Kubínová L, Moravcová M,_Zi_zka Z, Krej_cí V. The branching pattern of villous capillaries and structural changes of placental terminal villi in type 1 diabetes mellitus. Placenta. 2012; 33(5):343-351

17. Morales CML, Zurita ORB, Heredia RG, Miguel Cruz López MC, Araceli Méndez Padrón AM, Juan Antonio Matute Briseño JAM. Placental atherosclerosis and markers of endothelial dysfunction in infants born to mothers with gestational diabetes] Med Clin (Barc). 2016;147(3):95-100.

18. Van Schaftingen E and Isabelle Gerin I . The glucose-6-phosphatase system. Biochem. J. 2002; 362, 513-532 (Printed in Great Britain).

19. Matsubara, S., Takizawa, T. and Sato, I. Glucose6-phosphatase is present in normal and preeclamptic placental trophoblasts : ultrastructural enzymehistochemical evidence. Placenta 1999;20: 81-85

20. Arion, W. J. and Nordlie, R. C. Liver glucose6-phosphatase and pyrophosphate-glucose phosphotransferase : effects of fasting. Biochem. Biophys. Res. Commun. 1965; 20, 606-610

21. Ghosh A, Shieh JJ, Pan CJ, Sun MS, Chou JY . The catalytic center of glucose-6-phosphatase. HIS176 is the nucleophile forming the phosphohistidineenzyme intermediate during catalysis. The Journal of Biological Chemistry.2002; 277 (36): 32837-42. doi:10.1074/jbc. M201853200. PMID 12093795

22. Newbern D and Freemark M. Placental hormones and the control of maternal metabolism and fetal growth. Curr Opin Endocrinol Diabetes Obes. (2011);18:409-16.

23. Drife, J. and Magowan, B. Medical disorders in pregnancy. In: Clinical Obstet \& gynecol. 2004; pp:327- 329.

24. Jansson, T.; Strand, Y.K.; Wennergern, M. and Powell, T.(2001). Placental glucose transport in gestational diabetes mellitus. Am. J. Obstet. Gynecol; 184(2): 111-16.

25. Graf-Schaefer, V.M.; Buchanan, T.A.; Xiang, A. 
Patterns of congenital anomalies and relationship to initial maternal fasting glucose levels in pregnancies complication by type 2 and gestational diabetes. Am. J. Obstet. Gynecol. (2000);182(2): 313- 320 .

26. Quinlivan, JA and Lam, D. Cholesterol Abnormalities are Common in Women with Prior Gestational Diabetes. Journal of Diabetes and Metabolism. 2013; 4 (4):1-4.

27. Schaefer-Graf UM, Meitzner K, Ortega-Senovilla $\mathrm{H}$, Graf K,Vetter K, Abou-Dakn M, et al. Differences in the implications of maternal lipids on fetal metabolism and growth between gestational diabetes mellitus and control pregnancies. Diabet Med. 2011;28:1053-9.60.

28. Quinlivan JA, Julania S, Lam L . Antenatal dietary interventions in obese pregnant women to restrict gestational weight gain to Institute of Medicine recommendations: a meta-analysis. Obstet Gynecol. (2011);118: 1395-1401.

29. Robinson JG, Wang S, Jacobson TA. Metaanalysis of comparison of effectiveness of lowering apolipoprotein B versus low-density lipoprotein cholesterol and nonhigh-density lipoprotein cholesterol for cardiovascular risk reduction in randomized trials. Am J Cardiol 2012;110:146876.
30. Ryckman,KK, Spracklen,CN, Smith, CJ, Robinson,JG and Saftlas,AF. Maternal lipid levels during pregnancy and gestational diabetes: a systematic review and meta-analysis. BJOG 2015;122:643-651.

31. Xie Y, Bowe B, Li T, Xian H, Yan Y, Al-Aly Z. Higher blood urea nitrogen is associated with increased risk of incident diabetes mellitus. Kidney Int. 2018;93:741-752.

32. Allison SJ. Diabetes: urea inhibits insulin secretion in CKD. Nat Rev Nephrol. 2016;12:581.

33. Feng $\mathrm{P}$, Guangli W, Qian $\mathrm{Y}$, Wei Z and Chongke Z. First-trimester blood urea nitrogen and risk of gestational diabetes mellitus. J Cell Mol Med. 2020;24:2416-2422.

34. Beharier O, Shoham-Vardi I, Pariente G, Ruslan S, Roy K, Yael B , et al.Gestational diabetes mellitus is a significant risk factor for long-term maternal renal disease. J Clin Endocrinol Metab 2015;100:1412-1416.

35. Rawal S, Sjurdur F O, Louise G G, Ronald CM, Stefanie NH, Charlotta G, et al. Gestational Diabetes Mellitus and Renal Function: A Prospective Study with 9- to 16-Year Follow-up After Pregnancy. Diabetes Care. 2018; 41:1378-1384. 